\title{
Towards social arboriculture: Arborists' perspectives on urban forest labour in Southern Ontario, Canada
}

Adrina C. Bardekjian ${ }^{1}, \mathrm{MFC}, \mathrm{PhD}$

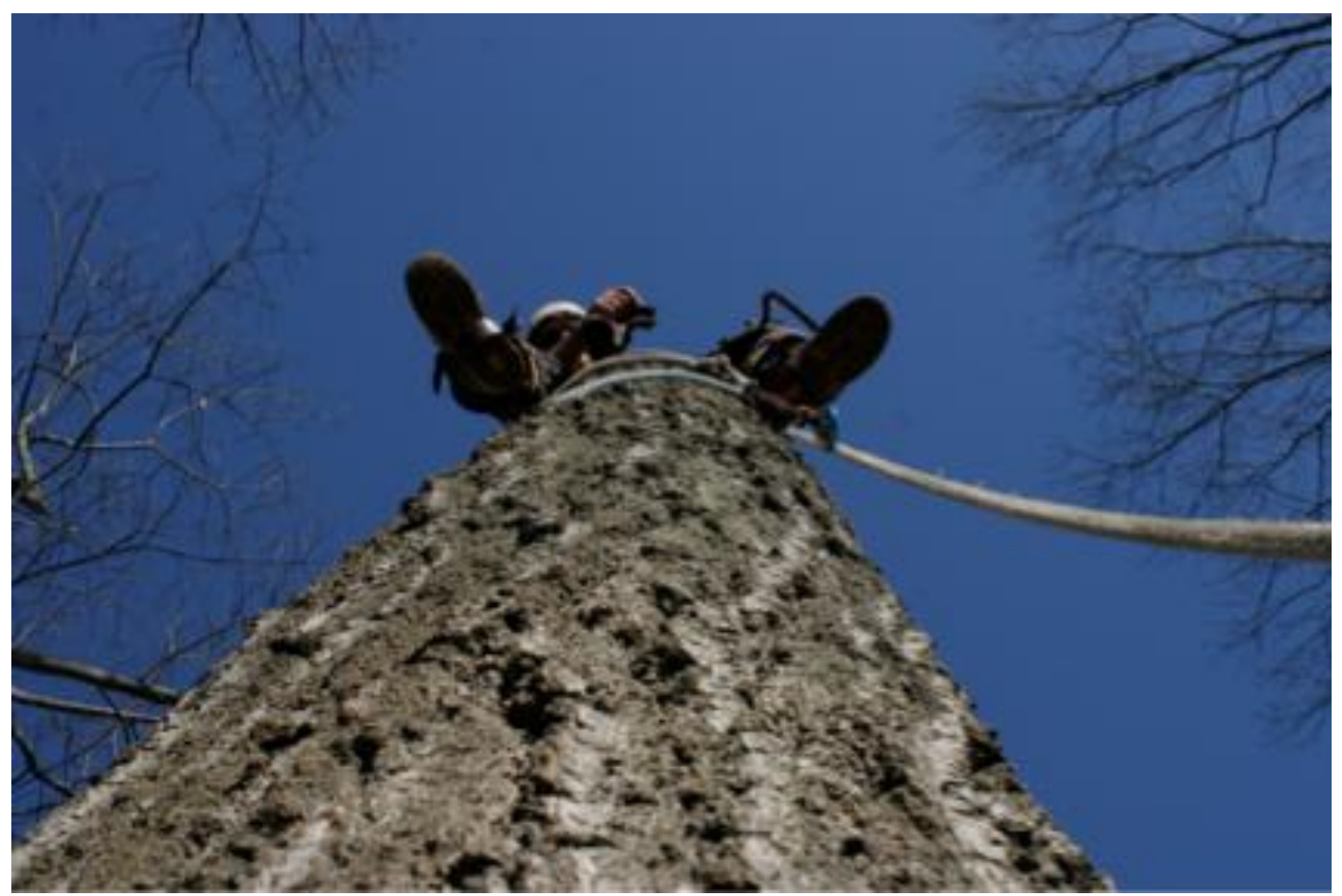

Figure 1. Arborist sitting atop a removal in progress: Toronto, Ontario, photo. Source: Adrina Bardekjian, 2010. 


\begin{abstract}
This paper explores how arborists negotiate their work environment, including the pressures of policies, the labour market, technologies, government regulations and lack thereof, and the non-human agencies with which they are confronted. The political climate surrounding urban forestry in Southern Ontario influences and governs operations and physical labour. There are many (f)actors and conditions (both external and internal) surrounding fieldwork in urban forestry and that these affect work and personal lives. The questions guiding this paper include: a) How do various political and labour conditions impact arborists' sense of pride, independence and skill?; b) What are the social and labour divisions within the culture of arboriculture?; and, c) What is the lived experience of urban forest workers, their employment, and what is it like to be a frontline worker? This paper provides a closer look at licensing, work conditions, subcultures and social dynamics in urban arboriculture. Using accounts from semi-structured interviews with arborists across Southern Ontario and by examining field arborists' activities, relationships with coworkers and working conditions through participant observation and ethnographic field notes, I explore and reveal how arborists feel about their working environment and the labour processes and people who oversee and surround them. Findings reveal that despite dehumanizing (f)actors within the field, there are elements of resistance and negotiation, and potential for an alternative future.
\end{abstract}

\title{
Keywords:
}

Agency; Environmental justice; Governance; Narratives; Political ecology; Social inclusion 


\section{Introduction}

A situation I experienced many years ago during a competition: I had to ascend 50 feet into a tree using a foot-lock method, when I got close to the top, the knot failed and I slid all the way down... The Ontario competition now bans that particular... Fortunately there was a well-respected arborist from another province [who determined that] the further I climbed up the tree, the weight of the double line couldn't compensate [for my weight], and how that hitch makes this little bend in the double line, it straightened it out, and that's why I slid. But the regulatory body, they just banned it completely and I feel upset because it effects everybody in Ontario wanting to use that particular knot which is well known all over the world (Interviews, 2012).

Political ecology raises questions about environmental justice, conflict and marginality; it deals with how land, and people are often displaced and disenfranchised. Examples in urban forestry include greenspace distribution and public rights of access (Heynen, 2003) and Mark Whitehead's The Wood for the Trees: Ordinary Environmental Injustice and the Everyday Right to Urban Nature (2009). Much like how the social constructionists ascertain that every perspective is human-centric, the landscape of power polarizes urban greenspace (Mitchell, 2002), and the urban forest, in turn, reflects changes in power structures and relations (Konijnendijk, 2008). This leads to questions of social equity and how this impacts the use and abuse of managing natural resources in relation to attitudes and practices toward urban green infrastructure, such as urban trees, parks, courtyards, school grounds, cemeteries and peri-urban woodlands. In addition, how people experience their physical spaces is guided, governed, influenced and manipulated by political and economic processes (Heynen, Kaika \& Swyngedouw, 2006). Arborists are the frontline workers in urban forestry, but it is unclear how arborists experience the urban forest, how they navigate it, and how they are positioned visa-vis the policy landscape that governs the urban forest at different scales. In short, what are the social implications of such a dangerous job? Dove $(1994 ; 1995)$, argues that the traditional foresters working within the confines of an industry or government are often overlooked by scholars as possibly having opposing voices. Robbins (2004) explains "their official context constrains their imagination of the world in a specific way" (p. 211). He goes on to state, that:

... that they are often poor people, in marginal economic positions, with peculiar local ecological knowledges, situated within confined fields of agency by socio-economic structures of environmental control and power... (Robbins, 2004). 
Urban political ecology recognizes human element in urban forestry with respect to power. By continually placing (compartmentalized) importance on trees or tree planting and the maintenance of trees for a purpose or function, urban forest practice can be seen as dehumanizing, whereby workers are secondary leading to feelings of alienation and resentment by workers (Braverman, 1974; Edwards, 1979). The common element of empathy in urban forestry discourse is directed toward children and communities (not necessarily worker communities) feeling good about being outside (followed by public health support). But what about the people working on those trees, developing relationships with trees, and then sometimes having to cut them down?

\section{Research Design and Methods}

Qualitative methods included a combination of: phenomenology - capturing lived experiences through stories and examining their meaning (Creswell, 2013; Finlay, 2012); discourse and metaphorical analysis - examining how arborists speak about themselves and each other, how others speak about them, and how they are represented in language (Schmitt, 2005); and, ethnography - examining arborists' activities, relationships with co-workers and working conditions first-hand. Results were gleaned from twenty-four semi-structured interviews, and participant observation (Atkinson \& Hammersley, 1994) with 50 field and consulting arborists across Southern Ontario.

\section{Site selection}

Rationale for site selection and criteria for specific study participants was influenced by personal interest, access and need.

\section{Participant selection}

All participants were municipal and private-sector arborists and urban foresters working in Southern Ontario. Most of them were engaged in operational tree care and some were involved in management and strategic planning work. Participants were recruited over email and/or phone and interviews were conducted in person or by phone. Interviews included a mixture of a standard set of questions asked of all participants, and free-ranging discussion.

\section{Participant description}

Participants represented a balanced mix of private sector and municipal employees: $85 \%$ were men; $63 \%$ grew up in urban areas; and, $95 \%$ were certified by the International Society of Arboriculture (ISA). They differed in stages of their careers, educational backgrounds and ages. Over $1 / 3$ were $31-40$ years old, and another $1 / 4$ were between the ages of 26-30. Almost none were younger, and the remainder was relatively distributed among the $41+$.

Human agency and experiences ensure that everyone will answer questions uniquely, but because of the complexity of human emotion and experience, it is 3 
difficult to control variables and determine what parts of collected data can be replicated. Thus, interpreting and elucidating data can be biased. To minimize this during analysis, I used direct interpretation (Stake, 1995, p. 78) and open and focused coding, with special attention to tonality and emotional expression in interviews to help overcome the subjective nature of qualitative interview data, and to achieve triangulation. I transcribed and triangulated my data to accurately decipher patterns and unify experiences.

\section{Results and Discussion}

Interviews revealed that despite dehumanizing (f)actors, there are elements of political resistance and negotiation by field workers, and that the notion of a "political climate" is intensely subjective. Two themes emerged, revealing first that arborists must work within the confines of systems that influence their performance; and second an insight on operational labour (e.g. hands-on, applied work practices). The existing political and economic climate surrounding urban forestry in Southern Ontario is classed and gendered, favouring male, non-field workers. There are many issues with which arborists contend due to the complexity of governance structures. Stories were wrought with emotion and intense adversity. Participants shared their experiences of disrespect and mistreatment; health impacts and consequences to family life; and their views on licensing and lack of standardization in the industry. Though there were many areas that interviewees addressed, I will deal with the most common themes, namely: a) how concerns about safety and security offer insights into personal inhibitions and uncertainties; and b) how inter-personal relations in the workplace affect the way field arborists conduct themselves and their work. Gender relations were also expressed in the power dynamics of daily practice, however I will not deal with that in this article.

\section{Safety and Security: Challenges, limitations and long-term health impacts}

Everyday there's liability all around you. You're working at heights. You are working with chainsaws... there's so many connecting links. The limb that we're tied into could fail, the rope that we're using could be easily cut... there's a whole chain of how we're connected to the tree has to be safe (Interviews, 2012).

The first theme under labour contentions included diverse perspectives on personal safety, methods and techniques, stories about teamwork, and costs to life at home. Respondents' perception on degrees of risks and challenges were relative based on their positions: where field arborists were most concerned with physical safety and operational challenges, consulting arborists were most concerned with professional liability and legal issues. Participants also made the distinction between physical safety and security (security being emotional validation and trust 
in others). My study shows that some interviewees were living in marginal socioeconomic positions, experiencing severe long-term health problems and daily risks of personal injury or fatality.

\section{Physical impacts}

There's so many hazard issues surrounding the tree and things that we cannot see (Interviews, 2012).

Conditions of operational tree work include long hours, inclement weather, and daily tasks focused on client requests, single tree management and construction aspects involving trees. Some companies offer additional services such as ecological restoration, plant health care and snow removal. The major practices of urban tree care include tree conservation (e.g. inventories, risk assessments, consulting, education) and tree work or operations (e.g. pruning, planting, cabling, fertilizing and removals). The line between risk-taking and risk-aversion in worker behaviour is amplified in these operations. Working conditions are complex and hard; field arborists careers are like "industrial athletes", they have a short window for hard physical labour; this was evidenced by my participants' age ranges.

Yet, despite the obvious physical dangers that come with outdoor tree work, safety includes more than equipment maintenance and wearing appropriate clothing. Alex Julius' study (2013) about occupational hazards in the arboriculture industry sheds important insight. According to Julius (2013), neglect with regards to safety procedures was with Personal Protective Equipment (PPE); only 50\% of arborists were wearing their gear. She goes on to say that arborists' attitude towards safety, emphasis is placed on abiding by safety regulations so that they do not get fined, but, she argues, attitude should be their personal safety first - so they do not die or get brain damaged (Julius, 2013). Through interviews and participant observation in Southern Ontario, personal safety, and safety for colleagues was the number one concern (secondary narratives).

For many interviewees, there was a constant internal struggle between the desire and passion to perform fieldwork and physical labour, and the limitations of age and physical ability:

This is my 20th year in the industry, so my body is broken in a lot of ways with the physical work (Interviews 2012).

Post-war technology has greatly influenced and aided the development of new systems and increased choices for tools (Dean, 2013). One participant explained the advantages of pulley systems to rig heavy limbs during removals (see Figure 2). For example, instead of having to lift the weight themselves, pulley systems allow climbers and grounds crews to use a fraction of their own physical strength thus reducing the chances of fatigue and potential long-term physical muscular strain. 

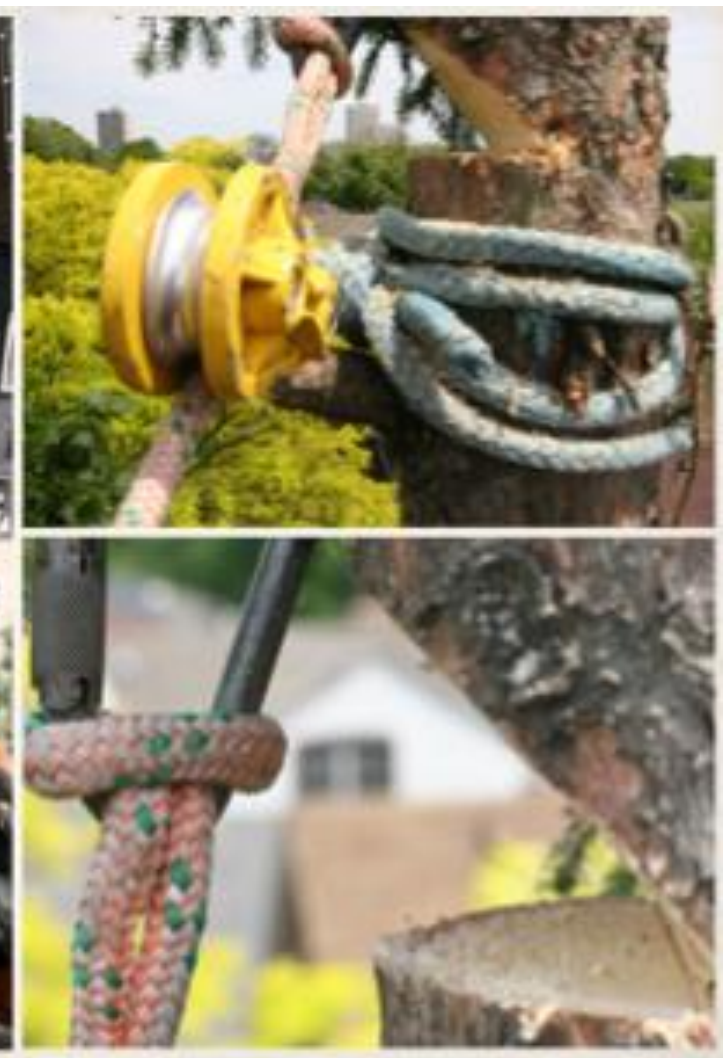

Figure 2. Spruce removal, rigging system: near Toronto, Ontario, photo. Source: ATSI, 2012.

Despite efforts to keep themselves safe from acute physical harm and make work easier, field workers experience long-term work-related musculoskeletal disorders (MSDs) (Logan, 2012), that effect all other aspects of their lives and wellbeing.

In 2011-2013 in Canada, there were three fatalities in the industry where climbers fell from trees. In addition, within the following six months of 2013, there were eight Critical Injuries reported to the Ministry of Labour (Arborist Safe Work Practices Committee, personal communications, group email, 2013). The Arborist Safe Work Practices (ASWP) committee met in late January 2014 to discuss the best method of addressing the prevention of accidents and fatalities in the trade.

\section{Home life and personal costs}

\section{My hands are numb - some days I come home and I can't pick up} my toddler (Interviews, 2012).

The long-term health impacts vary tremendously between the physical, emotional and psychological. For many participants work life dominated their home life and affected their relationships with family and friends. Interestingly, the majority of participants socialized mostly with friends outside the industry. Time 
and fatigue were the two common issues: coming home late, not seeing their kids before bed and/or being too tired to play, or participate in other domestic activities.

Balancing the various aspects of my life has been difficult. Working [at my regular job] consumes 40 hrs a week and my part-time business consumes another 25-40 hours a week in the field during peak season. Travel consumes a minimum of 10 hrs a week. That's 75-90 hours on the road. I sleep an average of 5-6 hours a night. There goes another 42 hours. I'm left with 26 hours. These 26 hours disappear very quickly. I can't precisely account for them (SMA, 2012).

One business owner reflected that being a good arborist does not mean one is a good businessman, and even when a company is failing, the pressure to keep it afloat is overwhelming due to the personal investment:

Go into business and immediately you abandon your focus on arboriculture for those other mandatory requirements under the law: accounting, remitting GST, HST, WSIB, IE, CPP, payroll. There's an endless struggle to try and keep it alive, because in order to get into it and set up everything, you've committed so much that you just keep on going, hoping that it will pay off (Interviews, 2012).

This "struggle" brought with it other frustrations about income and sometimes led to compromising one's integrity. Some often felt pressured to be permissive; whether it was a fear of going to court; or of losing an important client (Interviews, 2012).

Field arborists often contend with a "work-hard, party-hard" subculture. Many expressed problems with substance abuse (e.g. drinking too much, smoking pot daily), some revealed that they had (undiagnosed) learning disabilities (e.g. ADHD) and struggled with literacy. Some participants also revealed that they struggle with stress and anxiety due to the nature of their work. One participant stated: "People don't realize what a hard job this is." Some municipal workers have minimal provisions to take a leave of absence if they enroll in a city rehabilitation program, but as a result there is no assurance of anonymity, thus making this option a deterrent for otherwise interested participants (Interviews, 2012). Participants who worked for private companies did not always have this option and would have to take unpaid leave and pay for treatments.

The majority of my peers have had difficulty in school; many managing to get through various levels of education without having their learning disabilities properly diagnosed. These learning disabilities are not often obvious in the field because of the nature of our work (SMA, 2013). 
Coping tactics included socializing and hobbies. Not surprisingly, many spent time in outdoor physical activities (e.g. rock and ice climbing) and volunteering with their communities. All participants were family and neighbourhood oriented; they spoke about "giving back" and nurturing the landscape in multiple ways - not just by caring for trees during their "day jobs" but also by engaging people after hours as well.

\section{Security: Camaraderie, emotional validation and trust}

You become a closely-knit team and you rely on the eyes on the ground... it's really important to believe that the person on the ground, spotting for you, and supporting you is committed to your safety... or something is wrong (Interviews, 2012).

The concept of personal safety for outdoor tree workers goes beyond physical injury and extends to feelings of security, validation and trust. Due to the nature of working together in adverse and potentially dangerous situations, field workers place particular importance on having a good team that characterizes a unique work culture grounded in prioritizing camaraderie. I was humbled by the modesty of some of my participants and the way they spoke about their ground crews and how their lives can depend on how the rest of the team is functioning on any given day. Perspectives on fatalities were profound. Camaraderie and open communication was very important to all participants. This was apparent when discussing feelings of fear or discomfort

Over the last 10-15 years workers are more willing to speak openly about having accidents and feeling scared or apprehensive about dangerous situations. The Ministry of Labour releases information on accidents and organizes opportunities to discuss Post-Traumatic-Stress Disorder (PTSD). Participants felt that this increase in openness is due to organizations, in this case the International Society of Arboriculture, and having opportunities to network and connect with others about their experiences. The younger generation was more likely to communicate openly due to differences in generational culture and being more accustomed to sharing through social media (Interviews, 2012).

People are less afraid of looking foolish because they had an accident... if you look at the pool of older arborists who are still out there in the trenches, it may be that they're not on the inside with the groups who are interacting all the time. They're the older generation. Amongst the young people who are getting experience, there's a lot more interaction (Interviews, 2012).

Working relationship dynamics go far beyond an office labour environment. The influence of danger, death and the interconnectedness of the team members are 
bonding agents. In some cases of particularly close-knit groups, there was also a sense of 'us against them'; to non-field workers, it is not obvious how deep the relationships are, how important the relationships are: "Team work is everything" (Interviews, 2012)!

Yet, despite the close-knit sense of responsibility and ideals about teamwork, there is still disconnect among/between arborists. A big reason for this was the notion of conscious trust - needing to trust your team with your life and needing to trust that they have the same level of dedication and passion (see Figure 3). One common example was the high turnover in some companies: "It's difficult to get comfortable with the people around you if they keep changing" (Interviews, 2012). High turnover in employees impacted the level of trust and confidence that some participants had in fellow co-workers. Participants expressed the importance of human resource investment.

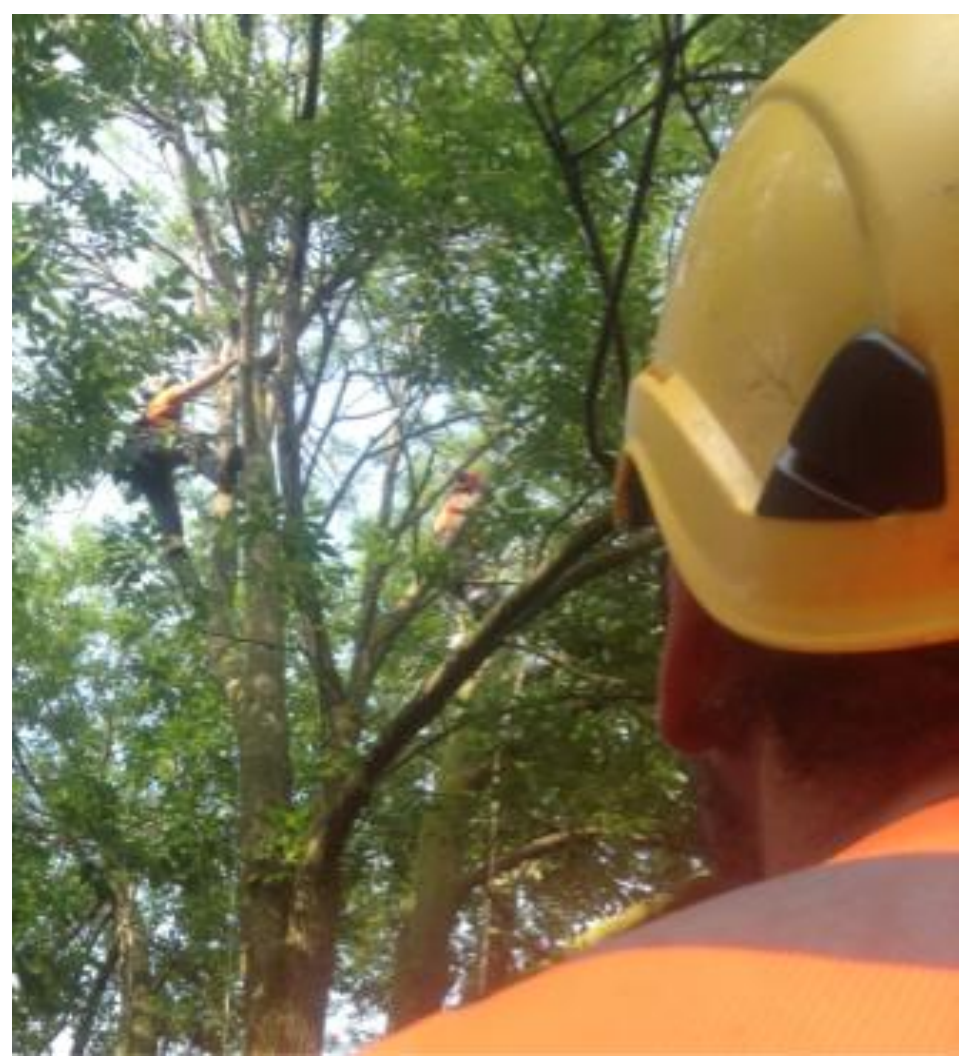

Figure 3. Grounds team looking up at climbers: near Toronto, Ontario, photo. Source: ATSI, 2013.

Lastly, health and safety concerns were not only about physical labour, legal concerns or even trust issues. A common example that came up was using the bathroom outside. One participant tried to explain the frustration:

Some clients are nice, they say straight away that we can use their washroom if we want, but most people don't offer. It's not realistic to have a port-o-potty in the back of a chip truck, and it's not 
what are we supposed to do? (Interviews, 2012).

Another interviewee commented that clients who offered workers their homes to use the bathroom were "not the wealthier clients", raising the questions about socio-economic stereotypes and privilege. Is health and safety a privilege in urban forestry? The Canadian Index of Wellbeing (CIW) is comprised of eight domains $^{1}$ that, collectively, can be used to measure the quality of life for Canadian populations. There is room for future research here in urban forestry by using the CIW to inform better health policies for outdoor workers. Opportunities for safety and knowledge have improved greatly in the last 20 years, but as interviews have revealed, this area needs critical attention.

\section{Polarized perspectives from pole-pruners to policies}

Discussions about contentions included perspectives on the role of government and existing policies and behaviour. Concerns that were raised influenced the way in which participants felt about their work environment and in some cases impacted their performance. In addition, participants felt strongly that licensing the trade would alleviate many issues.

\section{The 'us' versus 'them' dilemma: collegial contentions}

As professional 'rifts' became apparent, I began referring to these as the "versus dilemma". The two most common debates shaping power dynamics from interviews were the divisions between consulting (or "in office") arborists versus climbers stereotyping one another due to operational/performance differences; and, municipal versus commercial sector arborists stereotyping one another due to differences in management structures.

How can you hope to develop a policy about climbing if you've never climbed a tree (Interviews, 2012)?

This notes that climbing arborists can also be consulting arborists and vice versa. The real contention was with working hierarchies. One participant explained:

There are major issues between consulting arborists and climbers.

The consulting arborist looks down on the foreman, the foreman looks down on the climber and the climber looks down on the

\footnotetext{
${ }^{1}$ Community Vitality, Democratic Engagement, Education, Environment, Healthy Populations, Leisure and Culture, Living Standards, and Time Use. 


\section{grounds team. They need to understand that they all work for a} team (Interviews, 2012).

In some cases, climbers and field workers were stereotyped as being uneducated and rough. On the other hand, non-climbing arborists in managerial positions were not considered "real arborists" by their counterparts (Interviews, 2012). Feelings of resentment surfaced in this discussion as field workers felt that they had more of a connection with the forest. In this case, communication is key and has major implications. Yet, despite the extreme stereotypes, interviews revealed that both climbers and non-climbers held each other in high esteem because ultimately the two roles serve very different functions in the milieu of arboriculture and urban forestry, and as such, there are differences in how they understand trees and their perspectives toward policies.

The second rift that emerged from my interviews was between municipal and commercial arborists. For many participants, the main difference between the two was that the practice of commercial arboriculture placed more emphasis on profits and revenue first, whereas municipal arboriculture placed more emphasis on safety first, because they had more time to do a better job since funding does not depend on production - a presumption that is not necessarily true (Interviews, 2012). Many personal contentions stem from a feeling of a lack of appreciation; for commercial arborists, it came from the competitive nature of the business; for municipal arborists it came from working in a unionized environment (Interviews 2012). One participant described the difference as "two different classes": where commercial arboriculture was fast-paced, production-oriented, highly skilled, but suffered from high-turnover and occasional slips in integrity; versus municipal arboriculture where the environment is slower-paced with more emphasis on longterm planning, but less consideration for worker skill and continuing education. The main difference was that municipal field arborists had more time to care for trees over long periods of time. Whereas commercial field arborists are pressed for time to move on to the next job. As such, in the extreme stereotypes, commercial arborists were seen as "money-hungry" and municipal arborists were seen as "bucket babies," inferring laziness (Interviews, 2012). In both cases, power relations and their impact on self-reflection shape these feelings. In addition, some participants felt that there is a trend in contracting out labour and not investing in a well-skilled and educated municipal 'tree force' (Interviews, 2012).

The culture of each environment offers its own issues: "Municipalities can be vampires to someone's personal work ethic" (Interviews, 2012). The private sector may have more opportunities to do new and innovating things that municipalities may not be able to do given that programming allotments are typically based on what funding is available. Some described this as "having our hands tied with red tape." As such, field arborists who wanted to experience more areas within their industry preferred the culture of the private sector. "A municipality typically cares for their own trees, whereas a private company can care for both - they have more opportunity to care for the larger urban forest" (Interviews, 2012). This has many 
implications since, in the case of Southern Ontario, 80\% of the urban forest is owned privately (Interviews, 2012).

\section{Subjugation by standardization: Feeling undervalued by (mis)management}

A dominant narrative in political ecology is conservation and control. Here political ecology deals with how governments and social stigmas are used to dominate and subjugate land and space for political or economic agendas. One of the main examples for urban forestry here is urban sprawl and mass development. Although some may argue that developers must make concessions, to communities and urban forests, in order to build their plans, there are many accounts of urban parks being bought by developers to appease a growing urban population. Interviews revealed that arborists' voices are not being heard in this process effectively:

We as urban foresters and arborists have much less involvement in the design, and planning process... we are brought to the table very late... if at all. Usually we are involved after trees are declining and asked what to do. Maybe we haven't done enough to sell ourselves as true professionals? Perhaps we could do a better job in educating local officials of the skills and services we represent as a field of professionals? (Arborist on LinkedIn)

Increasingly, arboriculture and urban forestry fields have evolved into office work, relying on computers and technology, widening the gap between operations, planning and decision making. The majority felt it was difficult to have a voice in the decision-making.

One participant shared the story of a knot (see above) - one knot can mean the difference between getting up a tree faster, easier, alleviating physical stress and thus mental fatigue, that leads to sharper reflexes, better judgment and more efficient performance. At the end of a working day, (or after about 5 additional trees on average), the worker is not as tired. This story exemplifies the lack of consideration regarding integral aspects of operational labour when formulating standardized policies. Sometimes, regulatory bodies are in conflict with the climbers; there is not enough tie-in with the research or consideration for the people who such policies effect (Interviews, 2012). That is not to say that regulatory bodies are working against the safety of the climbers, but there is disconnect and clear lack of communication.

Feeling undervalued by their employers has fostered divisions among workers and managers, lowering productivity and quality of life. Little support exists for continuing education and professional development (e.g. conference attendance); little to no consideration for planning and decision-making; and low pay for the value of the job performed (Interviews, 2012). 
It saddens me that our supervisors, who are supposed to be leaders of a team don't take an active role in assisting their employees. The extent of their role seems to be that of granting "leaves of absences" when a particular employee finds themselves in a time of crisis. I suppose it's not surprising... a unionized environment, these days, carries people through their career. Opportunities are given to people on seniority if a minimal set of qualifications are met. Positions given out by peers, who too, have been carried by the union. Thus, the problem is systemic. I hope to witness a time when in my municipality there's as much emphasis on personal improvement and wellbeing as there is on traffic control or hydro safety. It may take many years and the death or retirement of many of these older people holding these positions of management. Perhaps if one day those in control have more education and a greater sense of responsibility to their employees, there will be less need for the protection from a union (SMA, 2013).

Many issues need to be unpacked in this statement with respect to physical and mental health, labour relations and governing structure. Participants felt that better support for field arborists depends on the sophistication and dedication of their employers - this would increase morale and reduce high turnover in employment. Participants who also managed crews and small businesses, expressed that high turnover in employment fosters a transient workforce and limited worker trust in other colleagues. Employers felt disappointed that more often than not, they were training current workers for their next job, and that this perpetuated an adverse cycle of management (Interviews, 2012).

Decision-making structures can be complex, depending on company or municipality priorities. Policy change is not always the outcome and not everything is planned and foreseen. Interviews revealed those in the political arena, have limited exposure to field activities, with discrepancies between what is reported and what is occurring. The voices of urban foresters and field arborists are not captured in current publications, creating a distance between field practices and the politics that govern them.

Since my employment began with 'the Corporation', I have witnessed a consistent practice by management to keep its arborists from feeling like a valued asset in the urban environment (Interviews, 2012).

The irony of this statement cannot be escaped as in W.H. Auden's, The Unknown Citizen (1939), a satire written about capitalism and standardization. Field workers want mandatory regulation; effectively standardizing the field yet they feel that uniform policies suppress individualism. This is the conundrum with which several participants expressed frustration. 
A counter-narrative (see Andrews, 2002) is that many municipal employees have private businesses or take on side-jobs during evenings and weekends to make additional income. Some participants felt that the updated "Conflict of Interest" clarification provided by the City of Toronto Auditor's office, is an example of a deliberate effort to further harm the field arborists of this municipality; that this is a "powerplay by the City" to limit worker capacity (Interviews, 2013). The different perspectives that emerged from interviews regarding the evolution of arboriculture within urban forestry in participant experiences best exemplify this.

I think [the evolution of the arboriculture industry] it's positive in a couple of aspects. There is higher emphasis on safety. Much greater emphasis on due diligence as it drives inspections and assessment of trees. There is a positive movement towards tree protection; that's just in the last decade. We've had some wonderful work done, led by Toronto, on tree bylaws and tree protection for Canada. There's been a strong growing knowledge and respect for what trees give to society. That's a good thing for us as professionals trying to work toward sustainable landscapes (Interviews, 2012).

Strong arguments for worker perspectives and the need for a municipal "Conflict of Interest" policy exist; however, there is a larger issue, regarding communication between management and workers - and the cleavage of silence is expanding. Another example of this involves the lack of enforcement of the private tree bylaw in certain municipalities (Interviews, 2012). Some participants felt that though the policy is advantageous, too many applications for tree removals are being approved. In that same vein, if a City felt the need to stop their own employees from working after hours in order to give opportunity to private companies (speculative in the case of Toronto's Conflict of Interest policy) than it is ironic that their own field arborists would be disgruntled about too many trees being slated for removal (in the case of a private tree bylaw).

Participants shared similar stories regarding public humiliation and general concerns about policies developed without employee consultation that directly impact their personal safety. Those who worked for municipalities discussed situations of public humiliation in front of colleagues due to labour policies. Here is one story that was posted on an arborists' personal Facebook page:

Today... the Supervisor of the unit yelled at me from across the parking lot. I was in the lot at my pickup truck assisting the Car Service Technician to get my driver-side door open. My keys were sitting in the ignition, and locked inside. We aren't supposed to be at our personal trucks before 2:50pm as quit time for outdoor City workers is 3:00pm. By being at my personal vehicle before 2:50pm, I was infringing on one of many municipal/union enforced rules, so the opportunity to amuse himself with a loud public berating of me 
was not missed. It's a style of management that is childish and disrespectful. A management system that is bred from a relationship between a Municipality and two civil unions [outdoor and indoor workers] (Posted on Facebook, 2012).

In the same post, another important issue was raised about the clothing that field workers are expected to wear:

The quality of City issued clothing is the cheapest available and of very poor quality. We are "Outside Field Arborists" but they dress us like "Outdoor Municipal Clowns." Not to mention the fireretardant treated material used without any cautions or precautions with regards to its potential dangers from continual exposure. For arborists around power lines it means the difference between an open and closed casket (Posted on Facebook, 2012).

This assertion reveals that health and safety issues are opposed by existing mandates. There are socio-psychological safety and wellbeing considerations that are unaccounted for in the existing mandate for required gear. There is also a connection here to the municipal vs. commercial debate whereby the private sector is safer because they choose better quality gear (Interviews, 2012). The underlying essence is that the lack of communication fosters these dichotomies.

Compounded with the above issues of feeling undervalued, are complexities for women in a male-dominated industry. Studies show that women are underrepresented in urban forestry and arboriculture and do not have the same opportunities as men (Kuhns, Bragg \& Blahna, 2002; Teeter, Bhai \& Bliss, 1990). Female participants shared stories of needing to work harder than their male counterparts to prove themselves, as well as being sexualized by colleagues and clients. However, this is changing as the role of women is increasing in the industry. I will not be tackling this discourse in this article.

\section{Lack of mandatory licensing}

Interviews revealed that there is a profound desire to move towards a Red Seal Trade. Under the new Ontario College of Trades Act, it is the College of Trades that has the mechanism to move a trade from voluntary to mandatory or regulated licensing. All felt strongly that the lack of mandatory licensing in Southern Ontario was the root cause of many of their complaints regarding labour concerns and standards. Having mandatory licensing, like in the state of Louisiana (Dozier \& Machtmes, 2005), the "Licensed Proficient Tree Surgeon" in the UK, the Certified Tree Worker Certificate in Europe (E. Neilson, personal communication, 2013: Tartu, Estonia), would give them a competitive market, make better income, achieve quality control, increase safety standards, foster positive public perception and improve the health of urban forests. 
Participants speculated two reasons for this gap: a) because trees are living organisms and are unrated structures: "Engineers shudder when they realize we're climbing into a tree"; and, b) because the industry has done a good job at selfregulating through the International Society of Arboriculture which provides a baseline for voluntary certification. There is a need in future research to focus on exploring whether these goals can be realized with mandatory licensing.

In 1992, the International Society of Arboriculture introduced and launched voluntary certification. Participants felt that the ISA has been the industry's saving grace as well its foundational grounding. There are six voluntary certifications that arborists may acquire: ISA Certified Arborist; ISA Tree Risk Assessment Qualification; ISA Certified Arborist Municipal Specialist; ISA Certified Arborist Utility Specialist; ISA Certified Tree Worker Climber Specialist; ISA Board Certified Master Arborist. Of the 234 registered arborists on the ISAO online public database, all are ISA Certified; this is the baseline to acquire any of the others; from here, 49 (21\%) have 2 credentials and 14 (.06\%) have 3 credentials, 1 registrant has 4 credentials. I was unable to obtain data on age and level of education for the registered provincial population. I was only able to show statistics on my own participants for this.

Yet, despite ISA's voluntary certification process (celebrating 20 years, 19922012), arboriculture in Ontario remains an unregulated trade. Many participants discussed the negative impact the lack of mandatory regulation has had on their field and in their personal lives and jobs. Participants felt that lack of mandatory licensing enables "weekend warrior" behaviour and fosters a lack of professionalism and keeps wages to a minimum, as competition is rampant (Bardekjian, 2015). Participants who owned their own businesses wanted the opportunity to compete for jobs with companies in their own caliber. They were frustrated with continually being out-bid by less qualified, uncertified, people who call themselves arborists. Participants felt that by having mandatory licensing, tree work can be properly priced for the deserving amount, rather than "bargain basement prices" driven by the lowest bidders and perpetuated by clients who only want to pay the least amount: "They're shocked when you tell them how much you charge."

Some participants expressed confusion and skepticism as to why standardized licensing is not in place. There is a disconnect in education and the messages being received by workers; if arboriculture is (indirectly) one of the most dangerous jobs in the world for the climbers/workers (I say indirectly because loggers, landscapers and roofers are among the top 25 on most lists); and the potential for damage in dense urban areas is so great; then why is it not mandatory to have a license to practice? One participant exclaims: "You need a license to cut hair for Pete's sake!"

The notion of mandatory licensing (shared by most field workers) is being overshadowed by the fact that the trade has been proactive in self-regulation. For instance, the Arborist Safe Work Practices Committee in partnership with Health and Safety Ontario developed a guide for doing tree care (Standard Operating Procedures). This document, the Arborist Industry Safe Work Practices 3rd Edition (2010), was done so successfully that the Ministry of Labour supports the use of that 
document when their inspectors are for the first time coming on a tree operation and wondering what the standards are for that kind of work (Interviews, 2012).

Some participants speculated that the Ministry of Labour would prefer not to have to administer mandatory regulation because it would need more people and thus cost them more money: "Enforcement is lacking - aren't we worth the Ministry's paperwork" (Interviews, 2012)? However, further examination included that the Ministry of Labour can look to the industry and say that they are self-regulated so they are doing well. Despite the progress and benefits of self-regulation, interviewees felt that the lack of mandatory licensing does nothing to raise the profile of tradespeople who deserve a better income.

We can do so much damage... the sector continues to be one of the most dangerous workplace sectors in the urban forest and in urban areas. Despite all of this the controlling authorities, provincial government, WSIB, Ministry of Labour, and Colleges and Universities continue to avoid the topic of mandatory regulation for practitioners in this trade (Interviews, 2012).

The notion of mandatory regulation for the trade was important to all arborists. Yet, however practical mandatory licensing may be, intellectually, "professionalizing" a field is not always a positive feat. The notion of a profession or a discipline suggests a specific body of knowledge (or canon) that is unchanging. It has many implications, politically and ethically and even contests notions of individualism; but fundamentally, interviews revealed that mandatory regulation would provide legitimacy to the work and to the workers. Taking a closer look at how the notion of licensing promises legitimacy for the trade and its workers is important when considering the critiques against standardization.

Several interviewees discussed relationship between identity crises and legitimization: "We would be better respected" (Interviews, 2012). Overall, by giving acknowledgement and placing importance on the job itself, it will foster worker selfconfidence in their role and pride in their work: "I think we just have a long way to go as far as getting this as a skilled trade, getting people to recognize what we do and why we do it and how we do it and trying to get away from this cowboy mentality" (Interviews, 2012).

Despite feeling undervalued and sometimes depreciated, there is pushback by workers and efforts to maintain some control in their workplace. This resistance occurs at the landscape level, where the statement "we can do so much damage," carries weight with respect to physical influence over trees and the impacts and affects of nature's agency (Bardekjian, 2015). To be clear, in addition to setting recognized standards for themselves with respect to quality control, participants also impressed the need for regulation for public safety, consumer protection and above all, urban forest health. 


\section{Conclusion}

Stories are powerful: they bridge language, culture, age; they resonate naturally into human minds; they nurture our sense of identity and foster community by building emotional connections (Roche \& Sadowsky, 2003). Participants' stories humanize the urban forest and advance society's understanding of issues such as invasive species, physiological impacts, gender roles, health care, and cultural diversity, while maintaining the material reality and integrity of nature itself.

Although community urban forestry is an existing concept in urban forestry discourse, the notion of the worker community is paid less attention to. Arborists are civic actors engaged in stewarding their community landscapes and fostering a long-term sustainability in multiple arenas. Examining current practices and narratives in urban forestry, inspired by political ecology, has revealed that we are missing the social aspects of practice and labour, and how these can influence broader critical thinking and strategic planning in Southern Ontario, towards social arboriculture.

There have been arguments that the continuous cyclical and systemic parlay of endless questions posed by political ecologists is politically and theoretically weak in attempting to offer concrete explanations and analysis (Peet \& Watts, 1996; Vayda \& Walters, 1999; Grove, 2009). Political ecology is useful in urban forestry for a paradigm shift; to move beyond commonly consumed frameworks of understanding (Kuhn, 1962), and to make real changes in urban forest policy (Perkins, 2011; Sandberg, Bardekjian \& Butt, 2014). Thus, by acknowledging the various under-represented stories with respect to labour and by using these narratives as a means to filling that social gap, urban forestry can become more integrated. This is how narratives can become powerful sources for integrative processes and the catalyst for change. Political ecology helped to showcase how dichotomies in governance influence operations; while my results are compelling, there is still a lot of work to be done on this important topic, to more effectively consider the social lives of workers. To this end, considering field perspectives is critical to proper governance in urban forestry and new policies on health and safety.

\section{Acknowledgements}

Thank you to L. Anders Sandberg, Cecil Konijnendijk van deb Bosch, and Patrick Hurley for inspiring me to explore political ecology. Thank you to Sadia Butt, Lindsay Campbell, Nate Gabriel and Julian Ambrosii for comments on initial drafts; and to the Totten Fellows of the USDA Forest Service NYC Urban Field Station for letting me develop this piece with them. 


\section{References}

Andrews, M. (2002). Introduction to special research: Counter narratives and the power to oppose. Narrative Inquiry, 12(1), 1-6.

Atkinson, P., \& Hammersley, M. (1994). Ethnography and participant observation. Handbook of qualitative research, (1)23: 248-261.

Auden, W.H. (1940). The Unknown Citizen. In Another Time. New York, NY: Random House.

Bardekjian, A. (2015). Learning from Limbwalkers: Arborists'stories in Southern Ontario's urban forests (doctoral dissertation). York University, Toronto.

Braverman, H. (1974). Labour and monopoly capital: The degradation of work in the twentieth century. New York \& London: Monthly Review Press.

Creswell, J. W. (2013). Qualitative inquiry and research design: Choosing among five approaches (3. ed.). Los Angeles: SAGE Publications.

Dean, J. (2013, February). Tools of the trade: The impact of post-war technology on arboriculture. Conference presentation at the ISA Ontario Chapter Annual Conference.

Dove, M. (1994). The existential status of the Pakistani farmer: Studying official constructions of social reality. Ethnology, 33(4), 331-51.

Dove, M. (1995). The theory of social forestry intervention: The state of the art in Asia. Agroforestry Systems, 30, 315-40.

Dozier, H., \& Machtmes, K. (2005). Arborists in Louisiana, U.S.: A baseline assessment of safety and professionalism. Journal of Arboriculture 31(5): 228234.

Edwards, R. (1979). Contested terrain: The transformation of the workplace in the twentieth century. New York, NY: Basic Books.

Finlay, L. (2012). Debating phenomenological methods. In N. Friesen, C. Henriksson, \& T. Saevi (Eds.), Hermeneutic phenomenology in education: method and practice (pp. 17-37). Rotterdam, Boston: Sense Publishers.

Grove, K. (2009). Rethinking the nature of urban environmental politics: Security, subjectivity, and the non-human. Geoforum, 40, 207-216. 
Heynen, N. (2003). The scalar production of injustice within the urban forest. Antipode, 35(5), 980-998.

Heynen, N., Kaika, M., \& Swyngedouw, E. (2006). (Eds.). In the nature of cities: Urban political ecology and the politics of urban metabolism. London, UK: Routledge.

Julius, A. (2013, January 25). Risking life and limb. ArborViews Podcast. Interview by Robert Polomski. Retrieved from: http://www.isaarbor.com/education/onlineLearning/podcastDetail.aspx?ID=8\&EP=853

Konijnendijk, C. (2008). The forest and the city: The cultural landscape of urban woodland. Denmark: Springer.

Kuhn, T. S. (1962). The structure of scientific revolutions. Chicago, IL: University of Chicago Press.

Kuhns, M.R., H.A. Bragg, and D.J. Blahna. (2002). Involvement of women and minorities in the urban forestry profession. Journal of Arboriculture 28:27-34.

Logan, M. (2012). In the field with Matt Logan: Education is the key for preventing \& treating MSDs. Arborist News, July/August, 14-16.

Mitchell, T. (Ed.). (2002). Landscape and power. Chicago, IL: University of Chicago Press.

Peet, R., \& Watts, M. (1996). Liberation ecologies: Environment, development, and social movements. London and New York: Routledge.

Perkins, H. (2011). Gramsci in green: Neoliberal hegemony through urban forestry and the potential for a political ecology of praxis. Geoforum, 42(5), 558-566.

Roche, L., \& Sadowsky, J. (2003). The power of stories (I): a discussion of why stories are powerful. International Journal of Information Technology and Management, 2(4): 377-388.

Robbins, P. (2004). Political ecology: A critical introduction. Malden, MA: Blackwell Publishers.

Sandberg, L. A., Bardekjian, A., \& Butt, S. (Eds.). (2014). Urban forests, trees and greenspace: A political ecology perspective. London, UK: Routledge.

Schmitt, R. (2005). Systematic metaphor analysis as a method of qualitative research. The Qualitative Report, 10(2): 358-394 
Teeter, L.D., Bhai, T., \& Bliss, J.C. (1990). Perspectives of women foresters in the South. Women Natural Resources. 12, 20-23.

Vayda, A., \& Walters, B. (1999). Against political ecology. Human Ecology, 27(1), 167. 